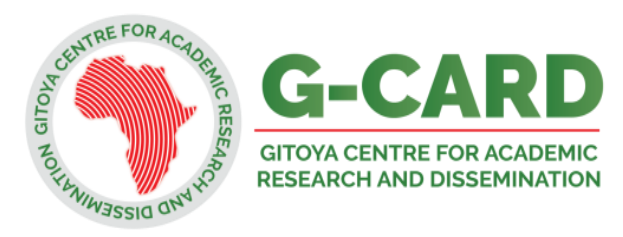

\title{
Perception of School Stakeholders on the Effect of School- Home Distance on Students' Academic Performance among Community Secondary Schools in Rorya District, Tanzania
}

\author{
Lilian Oneye and Daniel Onyango, PhD \\ Saint Augustine University of Tanzania
}

\section{Corresponding Email: oneyalily@gmail.com}

\begin{abstract}
The study sought to determine the perception of school stakeholders on the effect of school-home distance on students' academic performance among community secondary schools in Rorya District, Tanzania. The study employed a convergent survey design under the mixed research approach. The sample for this study was 100 respondents out of the population of 21,894 stakeholders, but only 87 responded. Quantitative data were collected through a questionnaire while qualitative data were collected through the interview. Quantitative data was analyzed using descriptive statistics while qualitative data was analyzed using thematic analysis. The study concludes that long distance travelled by students reduces teacherstudents contact time, leads to stomach ulcers, headaches and related issues which reduce school attendance and completion rates. The researchers recommended that community, government authorities and other stakeholders should make plans to build school dormitories or hostels to reduce the adverse effects of school -home distance.
\end{abstract}

Key word: School, home, distance, Academic Performance, community secondary schools

\section{Introduction}

Academic achievement is an important indicator for a future success of the learners. When students perform better, there is high chance for employment, thus reducing dependence rates among school graduates (Word report, 2019). As more countries struggle to achieve ambitious education goals, Education For All is in line with the Sustainable Development Goals (SDGs) initiated by the United Nations in setting targets for countries to offer children free and compulsory, equitable and quality primary and secondary education by 2030 (Human Right Watch, 2017). As a result, in 2005, approximately 512 million students joined secondary schools all over the world, marking a substantial increase of more than 73 million compared to the year 1999 (Mhiliwa, 2015. As a result, the trend of primary education with more enrollments has created the need for expansion of secondary education which requires adequate supply of teachers and appropriate schools learning environment.
In the context of Tanzania, just like in other countries, the construction of secondary schools did not pay attention to home-school distance experienced by potential learners. The overlooked factor includes other related concerns like transport challenges, meals availability, study time and safety issues the learners are likely to face.

Consequently, long-distance to and from school has been a topic of interest to scholars in various countries such as in America, Europe, Africa as well as Tanzania as the factor may affect students' academic progress and performance (Melack, 2014; World Bank, 2019). The problem occurs mostly in developing countries like Tanzania in which some of the students travel very long distance on foot or by bicycles to access education (Human Right Watch, 2017).

The students' long-distance schooling challenges have been experienced across all regions of Africa. In European countries, the issue of long-distance schooling is also experienced although it is not 
strongly related with students' performance due to socioeconomic differences in such countries like Finland, Germany, Sweden, the Netherlands, Belgium, Greece, Iceland, Ireland, Israel, Poland, the United Kingdom, Serbia, Russia and Dubai (OECD, 2011) as compared to African countries.

UNICEF (2017), in a compilation of the Guyana outof-school children study, found that home to school distance affects children's school participation due to physical barriers and the associated community surroundings. Sabean (2007) on reviewing distance from home to school suggested that for learners of primary schools, the maximum distance from home to school should be 1.6 kilometers and for secondary school students, the maximum distance from home to school should be3 kilometers.

The study of Raychaudhuri, Debnath, Sen and Majumder (2010) on factors affecting students' performance in Bangladesh established a positive relationship between minimal distance to school from students' home place and academic performance, though the association was not strong. In developing African countries, longdistance seems to be a major challenge in many countries. For instance, in Zimbabwe, students often travel for more than $20 \mathrm{kms}$ to reach the nearest secondary school (Chinowaita, 2015). A study by HRW (2017), reported that on average, some students in Tanzania use more than one hour and a half to get to school daily. In Uganda, the issue of students traveling long distances to school appears to be a problem too. In that context, Muhia (2015) established that long distance to school decreases the quality of communication between teachers and students, something which may affect the academic progress of the learners. Furthermore, because students spend a lot of time traveling at the time when they could be at school learning, the quality of their learning outcomes is likely to be affected too. Besides, Bashaiza (2016) reported that the long distance to school reduces student concentration in class as some of them reach school while sweaty, stressed and depleted physically and mentally, thus affecting learning.

Despite the initiative of building schools in every Ward being essential step in increasing access to secondary education to people of different areas in Tanzania, the challenge of long-distance specifically to students in rural areas still exists. Rural areas are characterized by scatted settlements making it very difficult to allocate schools where all students can access easily. With this regard, numerous studies have shown that long-distance is an issue of concern since it affects students' learning which also affects their performance.

A study conducted by Mhiliwa (2015) found out that school location determines the distance in which students have to get to school. Williams (2010) further observed that many students have to travel for many hours to get to school due to long distances, which in turn influences irregular attendance to school. The thirteen students interviewed admitted to be traveling to school for more than one hour and a half; others walked or used a bicycle to cover up to 20 or $25 \mathrm{~km}$. as a result, the students claimed that they spent their days at school tired because they had traveled long distances.

In Rorya District, there are 26 Wards with 25 public secondary schools. Despite a large number of schools in the District, students still experience travelling longer distances, which is contrary to Sarbian's (2007), recommendation on the maximal distance of up to 3 kilometers for secondary school students. In view of this, the issue of long-distance to school with its associated challenges should be addressed for equitable academic outcomes. It is also important to note that distance-related variables result in various school problems including poor attendance, increased dropout rates, low achievement and other social issues (Muhia, 2015, Debnath, Raydhaudhuri, Sen and Majunder 2010).

The government of Tanzania implemented free basic education in 2016 from standard one up to form four with an idea of strengthening the construction of new schools to increase secondary education accessibility. However, the efforts undertaken did not consider the distance-related variables and the magnitude to which they can affect students' academic performance. The statistics provided by UNESCO (2011) in Tanzania show that in 2006 , there were $54.6 \%$ of students in rural areas who were traveling more than five kilometers to school. Also, a study conducted by Mhiliwa (2015), revealed that the location of community schools in different countries especially in developing countries including Tanzania is far from the students' homes. Again Human Rights Watch (2017) found that students in rural areas of the country have to travel very far to get to school and many do not have access to a community secondary school in their wards. This shows that the 
same problem of long-distance identified by Mhiliwa (2015) and Human Rights Watch (2017) still exists and the most affected students are girls (Human Rights Watch, 2017). Following this background, the researcher explored on the perceived effect of distance-related variables on students' academic performance in community secondary schools in Rorya District, Tanzania as one of the ways of initiating various interventions in ensuring equal access to quality education to all students in the country.

\section{Literature Review}

Various studies have identified a strong bond between School- Home Distance and Students' Academic Performance among the Secondary School learners. School- home long distance is associated or linked with students' lack of breakfast and lunch, transport problem, inadequate students' safety, inadequate study time, lateness, temptation and tiredness that disrupt students learning.

Acham, Malde, Theron and Egal (2012) in their study on breakfast, midday meals and academic achievement in rural primary schools in Uganda found that poor performers had poor patterns of feeding due to long distances they travelled from home to school. This is due to the fact that the long distance prevented students from going back home for breakfast and lunch. Thus students found it difficult to keep on studying with empty stomachs.

Adefunke (2015) observed that in Bauchi State, Nigeria distance to school made it necessary for the students to use any kind of transport like walking by foot, thus resulted in truancy among students in community secondary schools hence affecting their learning. Truancy or absenteeism affects students in the sense that when a student is absent his /her fellow students proceed with learning and leave him or her behind.

Moreover, Melack (2014) established that long walking distance made students reach school very exhausted which resulted in poor concentration on the subject being taught and sometimes dozing in class hence failing to learn effectively. This is because of tiredness, students' minds and bodies fail to work effectively and efficiently, hence poor ability to learn. Thus, circumstances like this, act as an obstacle to effective learning because learning requires calmness of mind and if by any chance the learner is stressed, disturbed, is nervous, harassed, or is worried he or she cannot learn effectively.
Distance-related variables lead to tiredness and lateness among students hence reduces their time in learning. Furthermore, long distance may force students to leave from school early so as to avoid arriving home late (Human Rights Watch, 2017). This may cause students to miss the participation in extracurricular learning experiences like sports and games which take place after class hours.

Muhia (2015) argue that long distance reduces the time which teachers and students could be in contact because the students have to spend a lot of time in walking instead of being at school. Therefore, the long distance to school results in smaller time used in productive learning. According to Luneja (2001), if school distance is very far from home, adolescent girls who live in rural areas tend to abandon school due to susceptibility to sexual harassment which may affect them psychologically since on the way to school, their security is not guaranteed (Human Right Watch, 2017). Therefore there is a need to come up with strategies that reduce the long school home distance experienced by the learners in secondary schools.

\section{Research Methodology}

This section entails the research methodology and procedures employed to collect data relevant to the research objective of the study. It also addresses the research design, study area, population and sampling, research tools, piloting of research tools, Validity and Reliability, Data analysis procedures and ethical considerations.

\section{Research Design}

This study used a convergent parallel research design under the mixed-method approach. A convergent parallel design involves concurrently conducting the qualitative and quantitative elements in the same phase. The convergent parallel design was used because one data source may not be sufficient to provide required results.

\section{Population and Sampling}

The study population was parents, students, teachers, Heads of Schools (HOS), Ward Education Officers (WEO), and District Education Officer(DEO) from Rorya District. The consideration of this area is because it is found in a rural areas with scattered settlements. Thus, it was a suitable place to obtain data about the perceived effect of distance-related variables on students' academic performance. All community secondary schools in Rorya District were involved in the study. While systematic random 
sampling and stratified sampling were used to select students and teachers, snowball sampling was used to select parents and purposive sampling techniques were used to select the heads of schools, DEOs and WEOs.

\section{Research Tools}

This study used a questionnaire to gather data. The researchers personally administered the questionnaire to teachers and students in the field. In addition, they used interview schedules to collect data from the WEOs, HOS, DEOs and selected Parents as reflected in Table 1 . Both questionnaire and interview schedules were structured based on the purpose of the study which was to find out the perceived effect of home-distance on students' academic performance in community secondary school in Rorya District. Before data collection, the researchers administered the questionnaire in one of the community secondary schools in Rorya District which was excluded in the actual study for assessing clarity of the questionnaire. The study further carried out the pilot study in order to test the reliability of the instrument whereby the splithalf technique of measuring reliability was employed to 30 students and then from two equivalent halves scores were calculated through SPSS Version 20 to determine the stability. The study obtained a correlation coefficient of 0.73 from the result, and therefore the instruments were accepted for data collection.

\section{Data analysis}

Data analysis was done with the aid of Statistical Package for Social sciences (SPSS). Quantitative data was analyzed through descriptive statistics and presented by frequencies and percentages. Qualitative data was transcribed and analyzed thematically.

\section{Ethical Considerations}

Before data was collected, the researcher requested for permission from the St. Augustine University authority and Mara Region government authorities. During data collection, respondents were fully informed regarding the objectives of the study and were given freedom to participate or not. Anonymity and confidentiality were considered to avoid identification of respondents.

\section{Findings and Discussion}

As indicated in table 1 , the targeted sample in this study was 100 respondents out of the population of 21,894 school stakeholders but only 87 participated. The researcher distributed questionnaires to them and all the 87 managed to fill in and return the questionnaire. In addition, the interview was conducted with 13 respondents.

Table 1: Target Population and Sample Size

\begin{tabular}{llll}
\hline Population categories & Targeted population & Sample size & Sampling techniques \\
\hline Students & 17375 & 63 & Stratified sampling \\
Teachers & 167 & 24 & Systematic sampling \\
Heads of schools & 25 & 4 & Purposive sampling \\
Parents & 4343 & 4 & Snowball sampling \\
WEOs & 26 & 4 & Purposive sampling \\
DEO & 1 & 1 & Purposive sampling \\
Total & $\mathbf{2 1 8 9 4}$ & $\mathbf{1 0 0}$ & \\
\hline
\end{tabular}

Table 2: Perceived Effect of Distance Related Variables

\begin{tabular}{|c|c|c|c|c|c|c|c|c|}
\hline \multirow[t]{2}{*}{ Statement } & \multicolumn{2}{|c|}{$\begin{array}{l}\text { Strongly } \\
\text { Disagree }\end{array}$} & \multicolumn{2}{|c|}{ Disagree } & \multicolumn{2}{|c|}{ Agree } & \multicolumn{2}{|c|}{$\begin{array}{l}\text { Strongly } \\
\text { Agree }\end{array}$} \\
\hline & $\mathbf{f}$ & $\%$ & $\mathbf{f}$ & $\%$ & $\mathbf{f}$ & $\%$ & f & $\%$ \\
\hline Lack of breakfast and lunch decreases class participation & 2 & 2.3 & 4 & 4.6 & 39 & 44.8 & 41 & 47.1 \\
\hline Lack of security measures affects academic performance & 1 & 1.1 & 4 & 4.6 & 29 & 33.3 & 52 & 59.8 \\
\hline Transport problem affects students' academic performance & 3 & 3.4 & 11 & 12.6 & 30 & 34.5 & 43 & 49.4 \\
\hline Long-distances traveled reduces teacher-students contact & & & 2 & 2.3 & 40 & 46 & 45 & 51.7 \\
\hline
\end{tabular}

While the study sought to establish the perception of respondents on the effect of distance-related variables on students' academic performance in community secondary schools, the findings are presented in table 2.
The findings in table 2 show that $91.9 \%$ of respondents agreed or strongly agreed while only. $6.9 \%$ disagree that lack of breakfast and lunch decreases students' class participation. Additionally, the table indicates that $93.1 \%$ agreed or strongly 
agreed that lack of appropriate security measures affects academic performance.

Furthermore, the results in table 2 indicate that $83.9 \%$ agreed or strongly agreed that transport problems affect students' academic performance. Moreover, table 1 show that $97.7 \%$ agree or strongly agreed that long-distances traveled reduce Teacher-Students Contact-time. Therefore, respondents either agreed or disagreed that all the distance-related factors affect students' academic performance. The qualitative data through interview further revealed that low concentration, stomach ulcers, missing learning sessions, absenteeism and lack of time to compensate lost periods were the results of long travelled distance by students, which hindered effective performance. This implies that longer distance impedes the smooth learning environment for students, hence may lead to low performance. These findings agree with Muhia (2015) who indicated that learners who travel long distance to school experience a lot of challenges.

Furthermore, the qualitative data revealed that longer distance from home to school made majority of the learners to arrive late at school when the lessons had commenced, which led students missing the introductory part or the entire period which took place early in the morning. The data further indicated that some students arrived while tired and sweating due to long distance travelled. It is important to note that the tiresome experience may lead to poor concentration and therefore less effective learning experience which may in turn lead into poor performance. One of qualitative respondent, particularly indicated that "quality of instruction is being distorted as a result of long walking distance from home to school, which leads students to get tired, sweat, smell bad, hungry, missing lessons and fail to participate in extracurricular activities." Another respondent revealed that "while distance-related variables make students get tired, ill, and even arrive late, other effects include absenteeism, truancy, dropout, and being desperate with studies which may lead to low academic performance.

\section{Conclusions and Recommendations}

This section provides the conclusions and recommendations of the study:

\section{Conclusions}

Based on the findings, school stakeholders perceived that long distance travelled by students reduces teacher-students contact time, leads to stomach ulcers, headaches and related issues which reduce school attendance and completion rates and therefore hinder effective teaching and learning, hence result into low academic performance.

\section{Recommendations}

Based on the conclusions, the study recommends that parents, community, government authorities and other stakeholders should plan to build school dormitories or hostels to reduce the adverse effects of school-home distance in community schools. The study further recommends the building of more schools which are closer to where students live to avoid the long distance travelled by students to attend school.

\section{Reference}

Acham, H. Kikafunda, J. K. Malde, M. K. Theron, W. H. \& Egal A.A (2012). Breakfast midday meals and academic achievement in rural primary schools in Uganda; Implications for education and school health policy. Food\& Nutrition Research, 56 (11), 217.

Adefunke, S.E (2015). Truancy among public secondary school students: implication for counseling. Journal of Emerging Trends in Education Research and Policy 6(7), 331338.

Bashaiza, J. (2016). Performance: Why distance to school matters. Available from http://www.newtime.co.rw/section/read/2 01440/

Chinowaita, M. (2015).Rural teachers, pupils suffering in silence. Zimbabwe: associated newspaper of Zimbabwe (PVT).

Debnath, M., Raydhaudhuri, A, Sen, S \& Majunder, B.G. (2010) factor affecting students academic performance: A case of Agartala municipal council area. Bangladeshi-Journal of Sociology, 7(2), 34-41.

Human Rights Watch, (2017). I had a dream to finish school: Barriers to secondary education in Tanzania. Available from http://www.hrw.org/sites/default/files/acce ssible_document/tanzania0217-accessi blepdf

Luneja, N. (2001). Primary education for all in the city of Mumbai, India: the challenge set by local actors: school mapping and local level. 
Melack, D. N. (2014). Determinants of the poor academic performance of secondary school students in Sumbawanga district (Master's thesis). Sokoine University of agriculture, Tanzania.

Mhiliwa, A.J. (2015). The effects of school location on learner's academic performance (master's thesis).The Open University of Tanzania. Available from http://repository.out.ac.tz/1296/1/Dissertat ion_-Joseph_Mhiliwa.pdfh

Muhia, N. (2015). Who would have thought the distance to school had such an impact on the quality of education? Available from: http://aphrc.org/post/6016.

OECD, (2011). "Does where a student lives affect his or her reading performance?" in PISA 2009 at a glance, OECD Publishing.

Raychaudhuri, A, Debnath, M, Sen, S and Majumder, B. G. (2010). Factors Affecting Students' Academic Performance: A case study in Agartala Municipal Council Area. Bangladesh e-Journal of Sociology 7(2), 3441.
Sabean, C. (2007). Students walking distance review for Nova Scotia department of education. available from https://www.ednet.ns.ca/docs/ studentwa lkingdistance.pdf.

UNESCO (2011).Tanzania educational sector analysis: Beyond primary education the quest for balanced and efficient policy choices for human development and economic growth. Senegal: Regional bureau for education in Africa.

UNICEF (2017). Guyana Out-of-school children study. South America, UNESCO. Washington DC: Center for American progress.

Williams, D.T. (2010). The Rural Solution: How Community Schools can Reinvigorate Rural Education. Washington DC: Center for American progress.

World Bank (2019). Benin: the multiple benefits of school lunch. Available from http://world bank.org. 